\title{
Can Hypercholesterolemia Alter Euroscore II Predictivity in Smokers?
}

\author{
Tania Leme da Rocha Martinez ${ }^{1 *}$, Anita LR Saldanha', André Luis Valera Gasparoto서 ${ }^{1}$ Ana Paula Pantoja \\ Margeotto $^{1}$, Fernando Henrique Guarnieri ${ }^{2}$, Thomaz Braga Ceglias ${ }^{1}$ and Abel Pereira ${ }^{1}$
}

${ }^{1}$ Nephrology Department, BP - A Beneficência Portuguesa de São Paulo, Brazil

${ }^{2}$ IESP - UERJ - Universidade do Estado do Rio de Janeiro, Brazil

*Corresponding author: Tania Leme da Rocha Martinez, Department of Nephrology, BP - A Beneficência Portuguesa de São Paulo, São Paulo, Brazil.

Received Date: March 17, 2020

Published Date: April 01, 2020

\begin{abstract}
Although EUROSCORE II is a strong predictor of mortality, it is not completely exact. The literature presents several examples in which this parameter collaborates, but does not provide conclusive predictability. From a database of 950 adult patients and of both sexes from an Intensive Care Unit of a large tertiary hospital, smokers were selected, classified according to exposure levels, in a number of 81 in total. A regression was then performed using a linear model of least squares. Controlled variables: gender, age, diabetes, hypertension, body mass index and primary or secondary prevention. Formula EUROSCORE II in smoking patients presented associations with cholesterol and hypertension levels, which, according to statistical analysis, were not confounding factors.
\end{abstract}

Keywords: EUROSCORE II; Risk models; Mortality; Cardiac surgery; Cholesterol; Diabetes; Hypertension; Smokers

\section{Introduction}

The explanation of the value of EUROSCORE II to the patient at the time of his surgical indication meets an ethical need for bilateral decision-making in the patient doctor relationship. This procedure opens the opportunity for greater effectiveness of awareness regarding the control of modifiable cardiovascular risk factors. The justification for this conduct can be evaluated based on statistical estimates of Intensive Care Unit databases.

\section{Euroscore II}

1. Program for evaluation of operative risk in patients who will undergo cardiac surgery.

2. Parameters analyzed:

a) Age; gender (male or female); Creatinine clearance (> 85 , between 51 and $85,<51$, dialysis patient; extracardiac arteriopathy, mobility deficit; previous cardiac surgery;

b) Chronic lung disease; endocarditis in activity; critical preoperative status; insulin-dependent diabetes; NYHA classification; class IV angina; ejection fraction $(<21$, between
21 and 30; between 31 and 50, > 50); recent myocardial infarction; systolic pressure $(<31$, between 31 and 55, > 55); urgency (whether elective, urgent, emerging or desperate); thoracic aortic surgery; nature of the intervention (1 isolated revascularization, $>2$ revascularizations, revascularization and valve surgery or left ventricle aneurysm) [1-6].

\section{Objective}

To study the possible effect of hypercholesterolemia and other modifiable major risk factors in patients already with one of them, in this case smoking, on the value of Euroscore II.

\section{Methods}

From a database of 950 adult patients and of both sexes of an Intensive Care Unit of a large tertiary hospital, smokers were selected, classified according to exposure levels, in number of 81 in total. A regression was then performed using a linear model of least squares to estimate the effects of hypercholesterolemia on EUROSCORE II, controlling for a series of variables such as gender, age, diabetes, hypertension, body mass index and primary or secondary prevention. 


\section{Results and Discussion}

The data indicated by the regression had a significant effect on THE EUROSCORE II of the following variables, in the order of significance: hypercholesterolemia has, on average, and controlling by the other variables, 7.5 more than EUROSCORE II. That is, approximately $30 \%$ more on average. Hypertension also presented a variation of 3.69 points, equivalent to $14 \%$. The only significant differences in EUROSCORE II when controlled by the other variables were in relation to gender (men have a EUROSCORE 3.54 lower than women), age (an increase of 0.27 Euroscore II for each year more of life). The other variables were not significant at a level of 0.05 , even when considering the types of exposure to smoking $[7,8]$.

\section{Conclusion}

There is a deleterious effect that can be added to the smokers EUROSCORE II values by the concomitance of Hypercholesterolemia or by Hypertension.

\section{Acknowledgment}

None.

\section{Conflicts of Interest}

No conflict of interest.

\section{References}

1. Altman DG, Royston P (2000) What do we mean by validating a prognostic model. Stat Med 19(4): 453-473.

2. Nashef SA, Roques F, Sharples LD, Nilsson J, Smith C, et al. (2012) EuroSCORE II. Eur J Cardiothorac Surg 41(4): 734-744; discussion 744745.

3. Nezic D, Spasic T, Micovic S, Kosevic D, Petrovic I, et al. (2016) Consecutive observational study to validate EuroSCORE II performances on a single-center, contemporary cardiac surgical cohort. J Cardiothorac Vasc Anesth 30(2): 345-351.

4. Nezic DG (2019) EuroSCORE II was launched as a risk score model for prediction of in-hospital mortality in cardiac surgery. Eur J Cardiothorac Surg pii: ezz346.

5. Guida P, Mastro F, Scrascia G, Whitlock R, Paparella D (2014) Performance of the European System for Cardiac Operative Risk Evaluation II: a metaanalysis of 22 studies involving 145,592 cardiac surgery procedures. J Thorac Cardiovasc Surg 148(6): 3049-3057.e1.

6. Sullivan PG, Wallach JD, Ioannidis JP (2016) Meta-analysis comparing established risk prediction models (EuroSCORE II, STS Score, and ACEF Score) for perioperative mortality during cardiac surgery. Am J Cardiol 118(10): 1574-1582.

7. Howell NJ, Head SJ, Freemantle N, van der Meulen TA, Senanayake E, et al. (2013) The new EuroSCORE II does not improve prediction of mortality in high-risk patients undergoing cardiac surgery: a collaborative analysis of two European centres. Eur J Cardiothorac Surg 44(6): 1006-1011.

8. Lisboa LA, Mejia OA, Moreira LF, Dallan LA, Pomerantzeff PM, et al. (2014) EuroSCORE II and the importance of a local model, InsCor and the future SP-SCORE. Rev Bras Cir Cardiovasc 29(1): 1-8. 